HARTLEY : THE ABSORPTION SPECTRA OF

LXXXVI.-The Absorption Spectra of Some Metallic Solutions.

By Sir Walter Noel Hartley.

Konrad Schaefer (Zeitsch. wiss. Photochem., 1910, 8, 212) has investigated the absorption spectra of nitrates following the method described in two papers which $I$ had the honour of communicating to the Society (Trans., 1902, 81, 556; 1903, 83, 221). He confirms these observations in all particulars.

Schaefer examined solid potassium nitrate, and found the absorption band when the rays were transmitted through $0.37 \mathrm{~mm}$. of the salt to be almost identical with that of the $N / 10$-solution in water examined through $75 \mathrm{~mm}$.*

* I had previously examined thin layers of molten potassium nitrate, but found only a continuous absorption; it is obvious now that the film $0.5 \mathrm{~mm}$. was too thick. 
The selective absorption of the ultra-violet rays by the crystal proves that it is a property of the salt molecule, and is not indicative of any change in its constitution, such as might be caused by the formation of hydrates in aqueous solution by hydrolysis or by ionisation. Furthermore, it is evidence, as already established by experiments on ethyl nitrate (Trans., 1903, 83, 234), and by Schaefer's more extended work, that the alkyl nitrates have a different structure, because under no conditions do they show any trace of an absorption band.

The following quotation from Schaefer's paper calls for some remark: "In cases where the general absorption caused by the metal is very slight, as, for instance, in solutions of the nitrates of lithium, sodium, potassium, strontium, and barium, the complete identity of the $\mathrm{NO}_{3}$ absorption was established, notwithstanding that here the atomic masses of the metals, which according to Hartley should influence the vibratory motion of the $\mathrm{NO}_{3}$ group, exhibit marked differences. The relative differences in the atomic masses, which alone can enter into the question, are here, in fact, greater than in the groups $\mathrm{KNO}_{3}, \mathrm{AgNO}_{3}, \mathrm{TlNO}_{3}$, to which Hartley refers."

The author has not established any new fact affecting the solutions, and his criticism here appears to be based on an error or misunderstanding of the argument advanced, because in the original communication it is expressly stated that in a salt $\mathrm{MNO}_{3}$, where $M$ represents the metal, the velocity of motion of $M$ may be accelerated or retarded by the $\mathrm{NO}_{3}$ or vice versa, the rate of vibration being determined by the relative masses of the ions; we are dealing in fact with equivalent weights.

When the mass of the positive ion is $\mathrm{H}=1, \mathrm{~K}=39 \cdot 15, \mathrm{Ag}=$ $107 \cdot 93, \mathrm{Tl}=204 \cdot 1$, and so on, we have $\mathrm{NO}_{3}=62$; but for $\mathrm{NO}_{3}=62$, we have $\mathrm{Cd}=56, \mathrm{Th}=58$, and $\mathrm{Pb}=103 \cdot 3$, from which it may be seen how much greater the relative or equivalent masses of $\mathrm{Ag}, \mathrm{Tl}$, and $\mathrm{Pb}$ are than that of $\mathrm{NO}_{3}$. Similarly, the differences in the equivalent weights of the metals $\mathrm{Zn}=32.5, \mathrm{Mg}=12, \mathrm{Ca}=20$, $\mathrm{Sr}=43 \cdot 5, \mathrm{Ba}=68 \cdot 5$, and of the group $\mathrm{NO}_{3}=62$, are too small to have any appreciable effect on the absorption spectra, especially as the bases exert little absorption, if any at all, in the region of wave-lengths usually photographed.

Schaefer further states that silver and thallium each exert a general absorption peculiar to the metal, which accounts for the differences in the absorption spectra of their nitrates, and that the difference is proportional to the combination of the metal in the undissociated molecule.

This statement is quite in accord with my observations and with 
the conclusion that the absorption spectra are due to the nitrate molecule in each case, whether as nitric acid or a metallic nitrate, that the salt molecule is not necessarily dissociated, and that the increased general absorption observed in solutions of these salts is accounted for by the high values of the atomic weights of the metallic elements. The question which arises, however, is: Does the general absorption caused by these elements extend so far down into the less refrangible rays as to interfere with or modify the absorption bands belonging to the $\mathrm{NO}_{3}$ group as observed in dilute solutions? In the case of thorium and erbium salts, which were the subject of experiments, the answer was in the negative, but the measurements of the erbium and thorium chlorides were not quoted (Trans., 1903, 83, 221).

No independent examination of the absorption spectra of any pure salts of the elements in question appears to have been made other than of the nitrates, and I have therefore reinvestigated salts of thorium, thallium, silver, and lead, and have tabulated the results.

This course has been deemed advisable because Schaefer examined mixtures of sodium nitrate with sulphates of other metals, and drew deductions from the absorption curves of such mixtures instead of comparing solutions containing equivalent quantities of the pure salts. Solutions of thallous nitrate and silver nitrate do not conform to Beer's law, as Schaefer observes, strong solutions showing a nroportionately greater absorption.

The absorption spectra of silver are particularly interesting, as may be seen on reference to Trans., 1902, 81, 572, where nitric acid, potassium nitrate, and silver nitrate are compared.

It is necessary here to quote only the figures derived from solutions of the latter salt, and compare them with solutions of silver sulphate.

\begin{tabular}{|c|c|c|c|c|}
\hline $\begin{array}{l}\text { Layer of } \\
\text { liquid. } \\
\text { mm. }\end{array}$ & Concentration. & $\begin{array}{c}\text { Spectrum } \\
\text { continuous } \\
1 / \lambda .\end{array}$ & $\begin{array}{l}\text { Absorption } \\
\text { band. }\end{array}$ & $\begin{array}{c}\text { Rays } \\
\text { transmitted }\end{array}$ \\
\hline $\begin{array}{l}10 \\
10\end{array}$ & normal & 3002 & ${ }^{1 / \lambda} \quad 1 / \lambda$. & ${ }^{1} / \lambda$ \\
\hline 5 & ", & 3069 & 3069 to 3535 & to 3706 \\
\hline 4 & ," & 3069 & 3069 to 3540 & 3652 \\
\hline 4 & & 3067 & 3069 to 3530 & 3638 \\
\hline 200 & $N / 20$ & 3069 & & \\
\hline 200 & $N / 20$ & 3067 & & \\
\hline 200 & $N^{\prime} / 40$ & 3069 & 3069 to 3579 & to 3900 \\
\hline 200 & $N / 50$ & 3148 & 3148 to 3579 & 3900 \\
\hline 200 & $N / 50$ & 3150 & 3150 to 8531 & 3888 \\
\hline 200 & $N / 200$ & 3149 & 8149 to 3504 & 3940 \\
\hline
\end{tabular}

Silver Sulphate, $107 \cdot 9$ grams of Ag per 40 litres. $200 \mathrm{~mm} . \quad N / 40$ Spectrum continuous to......... ${ }^{1 / \lambda} 4008$ 
The significance of these figures becomes apparent when it is understood that $10 \mathrm{~mm}$. of a normal solution are equivalent to $200 \mathrm{~mm}$. of $N / 20$-solution; $5 \mathrm{~mm}$. to $200 \mathrm{~mm}$. of $N / 40$, and $4 \mathrm{~mm}$. to $200 \mathrm{~mm}$. of $N / 50$. In the case of nitric acid and potassium nitrate, the two series of solutions yielded spectra which were identical. In the case of silver nitrate it will be seen that the measurements of the normal solutions differ from those which are more dilute photographed through equivalent thicknesses.

This indicates a change in the constitution of the solution. If now we compare these measurements with those of the spectra of silver sulphate, we see that the transmitted rays in the absorption spectrum of the latter salt extend beyond those of the silver nitrate of the same concentration, hence the specific absorption exerted by the silver does not limit the extent of the rays of the spectrum absorbed or transmitted by the silver nitrate solution.

\section{Thallium Nitrate.}

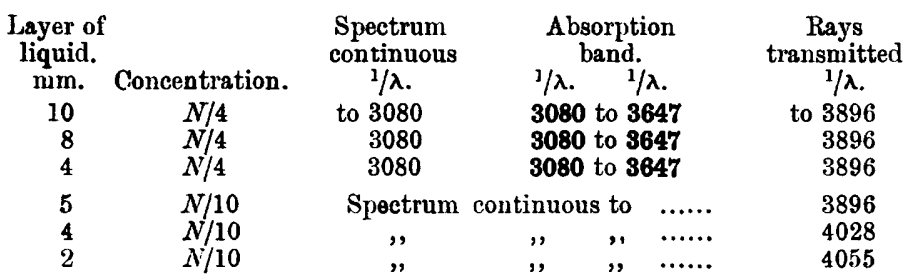

Thallium Sulphate, 204.1 grams of Tl per 20 litres.

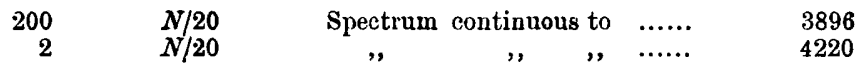

On examining these figures we find that 50,40 , and $20 \mathrm{~mm}$. of the $N / 20$-solution of thallium sulphate are equivalent to 10,8 , and $4 \mathrm{~mm}$. of the $N / 4$-solution of thallium nitrate, and that the three different thicknesses of the latter solution transmit exactly the same spectrum. Thallium sulphate is a sparingly soluble salt, hence the strength of the solution is $N / 20$; but it will be seen from $200 \mathrm{~mm}$. down to $2 \mathrm{~mm}$. the rays transmitted range from $1 / \lambda 3890$ to 4220 . The thickness of $200 \mathrm{~mm}$. is ten times as great as the equivalent of $N / 4$-solution, and twenty times as great as the $5 \mathrm{~mm}$. of the $N / 10$-solution; yet it transmits the rays freely. 
Lead Nitrate.

$\begin{array}{ccc}\begin{array}{c}\text { Layer of } \\ \text { liquid. } \\ \text { mm. }\end{array} & \text { Concentration. } & \begin{array}{c}\text { Spectrum } \\ \text { continuous } \\ 1 / \lambda .\end{array} \\ 15 & N / 2 & \text { to } 3062 \\ 10 & N / 2 & 3148 \text { feebly } \\ 5 & N / 2 & 3148 \\ 4 & N / 2 & 3272 \text { feebly } \\ 200 & N / 20 & 3021 \\ 200 & N / 70 & 3075 \\ 200 & N / 80 & 3075 \\ 200 & N / 90 & 3075\end{array}$

$$
\begin{aligned}
& \text { Absorption } \\
& \text { band. } \\
& 1 / \lambda \text {. } 1 / \lambda \text {. } \\
& \mathbf{3 1 4 8} \text { to } 3760 \\
& \mathbf{3 1 4 8} \text { to } \mathbf{3 7 6 0} \\
& \mathbf{3 2 7 4} \text { to } 3535 \\
& \\
& \\
& \mathbf{3 2 8 5} \text { to } \mathbf{3 5 3 7} \\
& \mathbf{3 0 7 5} \text { to } \mathbf{3 5 5 0}
\end{aligned}
$$

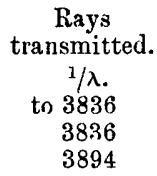

to 3674

3915

\section{Lead Acetate, 103.4 grams of $\mathrm{Pb}$ per 20 litres.}

$\begin{array}{rccccc}200 & N / 20 & \text { Spectrum continuous to } & & & \\ 2 & N / 20 & , & , & , & \end{array}$

The sparingly soluble lead salts do not admit of normal solutions being prepared, but it will be seen above that $200 \mathrm{~mm}$. of $N / 20$-lead acetate solution transmits continuous rays beyond those transmitted by $200 \mathrm{~mm}$. of $N / 20$-lead nitrate solution.

\section{Solution of Thorium Nitrate, $\mathrm{Th}\left(\mathrm{NO}_{3}\right)_{4}, 12 \mathrm{H}_{2} \mathrm{O}$.}

Normal solution $=62$ grams of $\mathrm{NO}_{3}$ and 58 grams of Th per litre.

Solution of Thorium Chloride of exactly the same concentration, that is, 58 grams of Th per litre.

The Nitrate.

Thicknesses of layer of liquid.

$\begin{array}{rc}\text { mm. } & 1 / \lambda . \\ 200 & 2787 \\ 100 & 2877 \\ 50 & 2980 \\ 20 & 3002 \\ 15 & 3065 \\ 2 & \text { Absorption band } \\ & 3354 \text { to } 3510 \\ & \text { Rays transmitted } \\ & 3510 \text { to } 3960\end{array}$

The Chloride.

$\begin{array}{cc}\begin{array}{c}\text { Thicknesses of } \\ \text { layer of liquid. } \\ \mathrm{mm} .\end{array} & \begin{array}{c}\text { Rays } \\ \text { transmitted. } \\ 1 / \lambda .\end{array} \\ 200 & 3043 \\ 100 & 3638 \\ 50 & 3638 \\ 40 & 3761 \\ 30 & 3825 \\ 20 & 3886 \\ 15 & 4115 \\ 10 & 4321 \\ 5 & 4368 \\ 4 & 4413\end{array}$

Comparing the absorption of rays exerted by the thorium nitrate with that of the thorium chloride in solutions of the same concentration, it will be seen that the chloride through $200 \mathrm{~mm}$. shows no band at any thickness down to $30 \mathrm{~mm}$; and it transmits a continuous spectrum extending beyond the band of absorption exerted by thorium nitrate and nitrates generally through only $2 \mathrm{~mm}$; from which it is evident that the thorium alone by its 
specific absorption does not limit or obscure the absorption exerted by the nitrate.

The sparing solubility of thallium and silver sulphates, and of lead acetate necessitates the examination of more dilute solutions than those of their nitrates, but similar evidence leads to the same conclusion, namely, that no metal of the group, thallium, silver, and lead, by its specific absorption, obscures or interferes with the absorption spectrum of its nitrate, notwithstanding that each of them, like the metal thorium, shows a distinctive general absorption.

Schaefer states "the differences in the absorption spectra of inorganic nitrates, which Hartley first found, have been confirmed. Nevertheless, I cannot agree with the conclusions which Hartley drew from them." He believes that the cause of the differences observed in some of the absorption curves is more chemical than physical in its origin. In this connexion I have particularly described the chemical action of light on some of the solutions. The action was evidently preceded by hydrolysis, and it eventually led to the precipitation of hydrated peroxides of cobalt and of manganese. Likewise, thorium nitrate and chloride formed precipitates of basic salts. Similarly also, basic compounds were deposited from bismuth and lead nitrates. In such cases there is, of course, the formation of free acid.

In connexion with this subject it is necessary to refer to the work of Ernst Müller (Ann. Physik, 1906, [iv], 21, 515). He determined the absorption power over a considerable part of the spectrum, of copper sulphate, nickel sulphate, potassium chromate, and cupric chloride solutions. He found it impossible to explain the colour changes which accompany dilution on the basis of dissociation alone; other factors which must be taken into account are the formation and decomposition of hydrates and complex molecules or ions. The colour of a dilute solution cannot under the influence of heat be made to correspond exactly with the colour of a cold concentrated solution.

It appears to be probable that small differences in the absorption curves of the spectra of solutions of nitrates in which the metal exerts no marked general absorption, may be explained by what has already been proved, namely, that many nitrates are hydrated in solution, others are hydrolysed, and the nitric acid then becomes hydrated (Trans., 1903, 83, 658, and Notes on the Constitution of Nitric Acid and Hydrates, Sci. Proc. Roy. Dublin Soc., 1905, 10, (N.S.), 373).

H. Erdmann isolated, crystallised, and examined the properties of five differently constituted nitric acids, four of which were 
826 HARTLEY : THE ABSORPTION SPECTRA OF PERMANGANATES.

discovered by Graham and one by Pickering, namely, metanitric acid, $\mathrm{O}_{\mathrm{O}} \gg \mathrm{N} \cdot \mathrm{OH}$; tetrabasic nitric acid, $\mathrm{O}<_{\mathrm{NO}(\mathrm{OH})_{2}}^{\mathrm{NO}(\mathrm{OH})_{2}} ;$ tribasic acid, $\mathrm{O}: \mathrm{N}(\mathrm{OH})_{3}$; octabasic acid, $(\mathrm{HO})_{4} \mathrm{~N} \cdot \mathrm{O} \cdot \mathrm{N}(\mathrm{OH})_{4}$; and the ortho-acid, $\mathrm{N}(\mathrm{OH})_{5}$.

Schaefer's experiment on solid potassium nitrate is a proof that neither ionisation nor hydrolysis is the cause of the appearance of the absorption band. Moreover, it is convincing evidence that the absorption spectrum of the solid salt is a property of the undissociated salt molecule, $\mathrm{KNO}_{3}$. At the same time, it is not incompatible with the hypothesis that the compound is in a condition of molecular strain, which may be due to the existence of unsaturated affinities in the compound. It may be presumed that it exists as a metanitrate, $\mathrm{O}_{\mathrm{O}} \gg \mathrm{N} \cdot \mathrm{OK}$, with the possibility of forming a tribasic compound, $\mathrm{O}: \mathrm{N} \cdot \mathrm{OK}(\mathrm{OH})_{2}$, or a pentabasic salt, $\mathrm{O}: \mathrm{N} \cdot \mathrm{OK}(\mathrm{OH})_{4}$, which is derived from the ortho-acid, $\mathrm{O}: \mathrm{N}(\mathrm{OH})_{5}$. 